\section{Impact of depositional facies on marine sedimentary pyrite textures and sulfur isotopes: a case study of the Early-Mid Pleistocene transition from the Valle di Manche section (Crotone Basin, Southern Italy)}

JENNIFER HOUGHTON ${ }^{1}$, DANIELE SCARPONI ${ }^{2}$ AND DAVID A. FIKE ${ }^{3}$

${ }^{1}$ Washington University in St. Louis

${ }^{2}$ University of Bologna

${ }^{3}$ Washington University in St Louis

Presenting Author: jhoughton@wustl.edu

Much of our understanding of the Earth's global sulfur cycle is based on stable isotopic proxies (e.g., $\delta^{34} \mathrm{~S}$ in sedimentary pyrite), measured in bulk samples and interpreted to record evidence of changes in global marine reservoirs over time. These interpretations tend to be relatively robust in deep marine environments with low/steady sedimentation rates, however in more commonly preserved shallow environments, regional or local processes may overprint such signals by modulating the delivery of sediments and organic matter that fuels microbial activity within sediments. We have constructed the bulk (cmscale) $\delta^{34} S_{\text {pyr }}$ record from the Valle di Manche section in the Crotone Basin, Southern Italy, preserving the stratal stacking patterns of two continuous transgressive-regressive cycles from the Mid Pleistocene. Interpreted in the context of detailed stratigraphic and co-registered paleoenvironmental records, gradual changes in bulk $\delta^{34} \mathrm{~S}_{\mathrm{pyr}}$ in offshore settings appear to be primarily driven by changes in sedimentation rate and organic carbon supply, while single-point anomalies found in inner-mid shelf deposits occur at abrupt changes in lithology or paleoenvironment.

The $\delta^{34} \mathrm{~S}_{\text {pyr }}$ bulk composition is a function of two major variables: (1) ambient $\delta^{34} \mathrm{~S}_{\mathrm{H} 2 \mathrm{~S}}$, affected by changes in microbial fractionation and/or distillation within porewaters, and (2) sulfide preservation as pyrite, occurring potentially intermittently over time in marine sediments. To evaluate this history hidden within the bulk $\delta^{34} \mathrm{~S}_{\mathrm{pyr}}$ signal, we have analyzed the $\delta^{34} \mathrm{~S}_{\mathrm{pyr}}$ of individual pyrite grains on the micron-scale using secondary ion mass spectrometry (SIMS) to characterize the distribution of values responsible for the observed bulk $\delta^{34} \mathrm{~S}_{\mathrm{pyr}}$ in samples throughout the section. All samples analyzed, regardless of bulk $\delta^{34} \mathrm{~S}_{\mathrm{pyr}}$ (ranging from -44 to $+7 \%$ ) and depositional setting (outer to inner shelf) contain a significant population of ${ }^{34} \mathrm{~S}$-depleted pyrite $(<-40 \%)$ with minima from -55 to $-50 \%$, suggesting that maximum (i.e., near-equilibrium) microbial fractionation $(\varepsilon \sim 70 \%$ ) is ubiquitous and that preservation of syndepositional pyrite occurs even in very shallow sediments or when post-burial pyrite formation skews the bulk $\delta^{34} S_{\text {pyr }}$ value. Some samples exhibit pyrite with overgrowth textures that cluster together in $\delta^{34} \mathrm{~S}_{\mathrm{pyr}}$ values and create bimodal distributions, suggesting that multiple, distinct episodes of pyrite formation can be 